\title{
An outline of military technological dynamics as restraints for acquisition, international cooperation and domestic technological development
}

\author{
Um delineamento da dinâmica tecnológica militar como \\ restrição para aquisição, cooperação internacional e \\ desenvolvimento tecnológico interno
}

http://dx.doi.org/10.1590/0034-7329201400306

ÉDISON RENATO SILVA* DOMÍCIO PROENÇA JÚNIOR **

Rev. Bras. Polít. Int. 57 (2): 99-114 [2014]

\section{Introduction}

Contemporary defense priorities assume that meeting the demand of the armed forces can lead to technological returns that will benefit national development, but fail to appreciate the different way each armed service uses technology. Both the National Defense Strategy (Estratégia Nacional de Defesa, Brasil, 2008) and the Brazilian White Paper (Livro Branco de Defesa Nacional, Brasil, 2012) assign technological responsibilities to the armed forces that go beyond their defense needs. They are expected to lead development-related technological research efforts. These are, succinctly, cyber technology to the Brazilian Army, nuclear technology to the Brazilian Navy and aerospace technology to the Brazilian Air Force. The assumption is that acquisition, international technological cooperation and domestic technological research by the armed forces will enable access to more advanced states of the art of technology, and that these will lead to technological returns and further national development. This broad expectation fails to take into account the very different ways each of the armed services deals with technology as a result of its specific combatant environment, and may misperceive what they can be reasonably expected to achieve in terms of development-related results.

\footnotetext{
** Alberto Luiz Coimbra Institute for Graduate Studies and Research in Engineering (Coppe), Federal University of Rio de Janeiro, Rio de Janeiro, RJ, Brazil (edison@ufrj.br).

** Alberto Luiz Coimbra Institute for Graduate Studies and Research in Engineering (Coppe), Federal University of Rio de Janeiro, Rio de Janeiro, RJ, Brazil (domicio.proenca.jr@gmail.com).
} 
The purpose of this text is to outline the ways the combatant environment conforms how each armed service deals with technology in pursuit of its responsibilities under the national defense mandate. It offers an overview of the problem formulation and solution seeking for tactical (use of force) and logistical (force creation, maintenance, disposition, displacement) purposes as a result of the relationship between the functional and strategic responsibilities of the armed services and specific technological states of the art. It develops the proposition of Strategic Studies as a core discipline for National Defense and International Security (Proença Jr and Duarte, 2007), contemplating the technological aspects that would underpin Brazilian decisions and considerations on the use of force (Soares Alsina, 2009). It subsidizes the assessment of Brazil's profile as a military power (Bertonha, 2010), adding to conceptualization efforts (Rudzit and Nogami, 2010) while pursuing the dynamics of technological advantage for combatant purposes (Proença Jr, 2011) and giving additional elements of resolution to comparative endeavors (Bertonha, 2013). It is far too early to propose a case study of Brazilian practices on this matter, but it is possible to outline elements that can help set it in context and supply some preliminary bearings.

The present text adopts a measure of conceptual rigor that distinguishes the parts of a polity's fighting force that is intended to fight in the air, at sea or on land as analytical categories that transcend whichever might be any one country's institutional arrangements for its armed forces (air forces, navies, armies, etc.). This allows the analysis to leave aside variations in the assignment of capabilities to this or that armed service, which is different from country to country. Therefore, the text considers the air fleet, which fights in the air, the sea fleet, which fights at sea, and the ground troops, which fight on land. This is the more rigorous perspective that allows a fruitful generalization of the technological dynamic associated with each of them, adapting Clausewitz's theoretical conceptualization of the fighting force and its concept of logistics (Clausewitz, 1976; Proença Jr. and Duarte, 2005). This means that the air fleet includes all combatant, combat support and service support elements that are intended to fight in the air - the whole of fighters and air defense, but excludes aircraft of all kinds intended to fight at sea or on land (antisubmarine or anti-tank aircraft, e.g.). The sea fleet includes all combatant, combat support and service support elements that are intended to fight at sea-the whole of ships, aircraft, ground installations (coast defense, e.g.) but excludes ships and troops (marines, e.g.) intended to fight on land. Finally, the ground troops include all combatant, combat support and service support elements that are intended to fight on land - the whole of troops, vehicles, aircraft, boats, ground installations intended to take part in the fight on land.

As a caveat, it is opportune to acknowledge that the analytical gain of setting aside individual countries' arrangements to focus on fundamental aspects of the combatant environments, for the purposes of appreciating technological aspects, means that some visible aspects of contemporary military affairs are necessarily 
left aside. There are three main elements that are not dealt with extensively in this article.

The first has to do with weapons of mass destruction, which admit being set aside as a particular kind of munitions, and thus can be considered as an alternative for fighting in the air, at sea or on land analytically. It is only the political consequence of their effects that sets them aside-and this aspect is not the focus of the present text (Gray, 2011).

The second has to do with points of contact between the use of the air, sea and land, such as special forces, amphibious and airborne forces. This is less of a problem: depending on their intended destination, they are simply ground troops that reach their targets by differentiated means (by air, by sea) with particular performance expectations, but are intended to fight on land; or they are a particular alternative for fighting at sea (torpedo-men, naval demolition, e.g.); a similar consideration would include their use for fighting in the air, albeit indirectly (special forces that target air bases or air-relevant installations, e.g., although they fight on land) (Dunnigan, 2003).

Finally, there are prospective possibilities, the most salient of which would be "cyberspace" and interplanetary space. The former is a construct upon materialities that exist somewhere on land, under the sea or that make use of the air for electromagnetic transmission. Peculiar cyber warfare techniques are only as relevant as much as any one particular aspect of, say, electronic warfare and do not justify, as yet, a treatment of their own (Dunnigan, 2003). The possibilities of the fight for interplanetary space are of a different order altogether. Low Earth Orbit does offer as much a combatant environment as the air or the sea. It is conceivable and it might eventually become proper to deal with "orbital fleets". However, despite the importance of the contemporary use of Low Earth Orbit for combatant and noncombatant purposes, the specificity of the forces that would fight for it and the associated technological dynamic is still largely prospective, even speculative (Klein, 2006). These are just about more than glimmers in visionaries' eyes but do not as yet warrant, thus cannot be treated, with the same solidity as air, sea and land-they will have to wait another occasion.

It is opportune to order the presentation in terms of the general outline of the strategic responsibilities (which admits nuanced similarity), the material and immaterial requirements, the pitfalls and hence the distinctive technological dynamic of the states of the art of the analytically derived armed services (Gray, 1993; Dunnigan, 2003; O'Hanlon, 2009). This allows a brighter contrast and allows for a more marked appreciation of how different the organizational outlooks of each armed service concerning technology must be. The presentation elects the issue of composition of effective fighting arrangements (the tactical and logistical states of the art, taken as a given) as the connecting thread of its presentation, discussing in succession the systemic integration of air fleets, the echeloned integration of sea fleets and the combined induction of ground troops. Brief 
comparative final remarks on the issue of the technological restraints on acquisition round out the outline intended.

\section{The systemic integration of air fleets}

The benefits that accrue from the ability to move forces and supplies by the air, to use force in the air for international political purposes are germane to the assessment, decision-making, discussion and analysis of international relations. The dynamic of air power is relevant to a wide variety of situations. These include the assertion of claims or rights of sovereignty; the interdiction of illegal drug, merchandise and people trafficking; the control of air space and, derivatively, of the ground and waters below it; the surveillance of borders and international areas in pursuit or support of international security, cease-fires and peace-building; the exercises of international environmental monitoring, commercial and emigration controls and peace keeping operations; the observation and enforcement of embargoes, no-fly zones and cease-fires; the security, safety and delivery of humanitarian relief. These are all in addition to the role of the air for counterinsurgency, conventional warfare, nuclear, chemical and biological warfare for the purposes of national defense. The current and prospective state of the art of air forces underpins the appreciation of the role they may come to play in international relations (Dunnigan, 2003; Murphy and McNiece, 2008).

A polity's air fleet comprises all combat, combat support and service support components of a polity's fighting force that aim to fight in the air. It results from a complex, multi-varied and usually continuous decision-making process. It takes into account the context, both in terms of the geographical realities that are politically relevant and in terms of the political relationships that are strategically pertinent. Those responsible for the political direction of a polity enunciate and modify existing and prospective air fleets in terms of policy direction and force design. They take into account alternative technological states of the art at the moment a decision is required, considering the availability of resources, the expectation of returns, and the estimates of risk associated with a given configuration of policy and force design for the air fleet, pondering its ability to enable the use of the air, particularly the use of the air by sea and land forces. From the point of view of the command of an air fleet, the result is a strategic portfolio of expectations and goals, missions and responsibilities, which translates into a set of means, modes of operation and methods that provide those capabilities that can best approximate the political goals enunciated by policy.

The technological dynamic of air fleets is in a constant state of flux because comparatively minor performance gains can translate into substantial advantage. A new procedure or adjustment can give a 5\% gain in range which can translate into being able to reach a hitherto unreachable target or afford potentially decisive more time in the air; a small gain in response time or sensitivity can move the 
advantage from one side to the other; a different method of preparation, rearming or refueling can increase the effective number of systems that can be brought to bear over time. Much of this is the result of situated exploitation of circumstances-they become possible against a given opponent, given a certain availability of resources (particularly, of learning by experience or study), or under certain transient political, informational, material, weather and geographical circumstances. This is a necessary aspect of air preparation and operations, from the composition of a given fighting package for one operation to the overall adjustment and articulation of command, logistic, sensor, communications, weapons, personnel and operational structures. The apparent constancy of headquarters (bases, squadrons, stations, e.g.) should not be mistaken for substantive stability of their capabilities. On the contrary, as marginal gains in performance in any one component of an air fleet can reconfigure what the whole might be able to do systemically, air fleets are constantly seeking those gains and alert to those of their prospective or actual opponents (Shaw, 1985).

The systemic nature of technology for fighting in the air illuminates the choices made by polities in the acquisition and composition of their air fleets. To take the capabilities of an air fleet by the performance of the aircraft it possesses is not enough. Albeit the specific performance parameters of individual aircraft models can be paramount to what an air fleet can and cannot do, they are in fact only a part of a much larger whole that explains what they can or might do. Air fleets are peculiarly dependent on robust and intimate connections between its components. Aircraft, weapons, systems, installations-speaking in terms of a system, all sensors, actuators, enablers and supports—must be systemically composed, organized and operated. In fact, they must be integrated in a largely homogeneous system: air fleets require systemic integration.

This is the inescapable result of the facts that (i.) each component of an air fleet is severely dependent on the others to function and (ii.) only the air fleet as a whole possesses the capabilities that can meet the expectations of policy. Air interception, the premier capability of an air fleet, requires compatibility among the surveillance and tracking sensors that detect an intrusion and can steer a counter against it; among the sensors that provide surveillance and tracking and those of the aircraft or system than can act against an intrusion; among the various sensors, countermeasures, guidance and munitions that may be used against the intrusion. Each component must operate with the others as seamlessly as possible, as only the whole can be expected to affect results. A break in any point of this chain risks failure: either because the intrusion is missed or mishandled; or yet because lack of compatibility might entail accidents or friendly fire. The relationships that enable the capabilities of an air fleet are truly systemic. The sum of its parts means little compared with the harmonious function of the whole, notably in terms of their real-time availability. Aerial systems have considerable, if frequent, downtime between and particularly immediately after operations; ample redundancies or 
extraordinary efforts are required to sustain serviceability rates above $50 \%$. The capabilities of an air fleet emerge from this systemic relationship, not from the individual capabilities of its components. Any consideration of an air fleet must take into account this inherent technological underpinning or gravely misperceive its capabilities (Crabtree, 1994).

As a result of the distinctive, systemically integrated co-dependency of its various components, polities face a stark choice in the force design of air fleets. Sunken costs, scale economies in maintenance (by far the largest cost over the service life of air systems) and economies of scope argue in favor of choosing to adhere to a given existing (or, more rarely, a prospective) technological state of the art. This takes the form of a given technical standard and effectively corresponds to a measure of affiliation to a given defense industrial base with its associated political consequences. The technological state of the art in an air fleet must be systemically integrated or risk ineffectiveness or even catastrophic failure. If a polity chooses to incorporate different technological states of the art, in effect it faces the reality of having two separate air fleets, each aligned to its own state of the art. In order to operate in this latter situation, it must acknowledge that this entails increased costs, the multiplication of support structures, the loss of systemic effectiveness and the burden of dealing with differing standards in all its operations.

\section{The echeloned integration of sea fleets}

The benefits that accrue from the ability to move forces and supplies by sea, to use force on the sea for international political purposes are germane to the assessment, decision-making, discussion and analysis of international relations. The dynamic of maritime power is relevant to a wide variety of situations. These include the assertion of claims or rights of sovereignty; the interdiction of illegal drug, merchandise and people trafficking; the control of trade, port access, coastal water, offshore resources and the wealth of minerals below it in the seabed; the surveillance of passage of cargoes and personnel through international and excluded maritime areas in pursuit or support of international security and peace-keeping; the exercises of international environmental monitoring, commercial and emigration controls and peace enforcement operations; the observation and enforcement of embargoes and cease-fires; the security, safety and delivery of ship borne transit and the provision of humanitarian relief. These are all in addition to the role of navies for counter-insurgency, conventional warfare, nuclear, chemical and biological warfare for the purposes of national defense. The current and prospective state of the art of navies underpins the appreciation of the role they may come to play in international relations (Hughes, 2010).

A polity's sea fleet comprises all combat, combat support and service support components of a polity's fighting force that aim to fight at sea. It results from a complex, multi-varied and regular decision-making process. It takes into account 
the context, both in terms of the geographical realities that are politically relevant and in terms of the political relationships that are strategically pertinent. Those responsible for the political direction of a polity enunciate and modify existing and prospective sea fleets in terms of policy direction and force design. They take into account the alternative technological states of the art at the moment a decision is required, considering the availability of resources, the expectation of returns, and the estimates of risk associated with a given configuration of policy and force design, pondering its ability to enable the use of the sea, and particularly the use of the sea by land forces. From the point of view of the command of a sea fleet, the result is a strategic portfolio of expectations and goals, missions and responsibilities, which translates into a set of means, modes of operation and methods that provide those capabilities that can best approximate the political goals enunciated by policy (Till, 2011).

The technological dynamic of navies is spread over a number of stages or steps that correspond to the different technological states of the art of its various components, usually out of choices made on particular occasions over a long period of time. What matters is the punctual performance of those components in the fulfillment of certain particular tasks as part of an ad hoc, transient sub-system made up to fulfill one particular mission, the "task force". Force design of a sea fleet is bound by the requirements of sustainability of largely self-contained components. The dominant among these are ships, but all other systems (aircraft, e.g.) tend to follow the same dynamic as result of their operational focus. This means that the support associated with each such technological state of the art is the paramount restraint for force design, modified by the considerable and extended downtime required to allow ships to operate. A ship typically spends $50-60 \%$ of its service life in maintenance, being unavailable for operations for many months. This lends a measure of stately regularity to the force design of sea fleets. Force design of sea fleets is marked by the regular but well-spaced replacement of whole steps, associated with tactical and logistical triggers that emerge when the performance of the components of a given step falls below the point where they can play a meaningful role in the composition of a task force (Dunnigan, 1993; O’Hanlon, 2009).

This lends peculiarity to the systemic nature of technology for fighting at sea, and illuminates the choices made by polities in the acquisition and composition of their sea fleets. To take the capabilities of a sea fleet by the ships it possesses is indeed to grasp the foremost part of its capabilities. However, this alone might not be enough. Particulars such as the peculiarities of underwater operations (mines, submarines, etc.), the pervasiveness of the use of the air in maritime operations and the reliance on land-based systems and installations can qualify the centrality of ships or, alternatively, lead to ships that carry such systems or aircraft themselves. Furthermore, albeit the specific performance parameters of individual ships can be paramount to what a sea fleet can and cannot do, they are in fact only the most salient part of a whole. Sea fleets rely on successive, transient, task-oriented, 
case-by-case instances of ad hoc association of its components. The sensors, actuators, enablers and supports of each component of a sea fleet are assets that can be composed, organized and operated as required, making use of differing individual capabilities expediently. In fact, they are loosely integrated components of a largely heterogeneous whole: sea fleets operate by echeloned integration.

Despite the role that sensor and communications support from land, air, space and seaborne systems can play in any one circumstance, it is the specific performance parameters of individual ships that remains dominant in establishing what a sea fleet can be expected to do. Ships are peculiarly self-sufficient in capability. They are designed and expected to operate with a considerable degree of autonomy at long distance from bases for extended periods of time. Over long periods of time, ships require robust and timely connections with shore resources, and may admit a limited measure of replenishment at sea by support ships. But they are designed to deal with most situations with their own shipboard resources over the period of their commission. Without paradox, however, the quality of shipboard resources is largely the result of proper preparation on shore. It is on shore that personnel can be selected, trained, assigned; and it is also on shore and the variety of aircraft, weapons, sensors, communications, combat and service support organizations can combine their efforts to provide the myriad of things that may allow a ship to mature an efficient and capable crew and be "ready for sea" (Speller, 2014).

Given the autonomous, largely self-reliant, nature of ships and the punctual nature of support from non-ship components once at sea, sea fleets are, and in fact must be, task-organized, (i) taking into account considerable variation of performance and capability among ships and other components, with (ii) the whole being the result of adequate combinations of the capabilities of the ships and other components that make up a task-force. Escort, the premier capability of a sea fleet, requires the appreciation of the differing capabilities of the ships involved. Depending on the expectation of the threat, a certain number and types of ships will be assembled that gather the differing kinds and qualities of sensors, weapons, sea worthiness, speed, autonomy, shipboard resources (e.g., communications) to make up an assembly that has reasonable expectation of success in carrying out the task. Each ship or component must be able to operate with the others, but this requires only that each can fulfill its own role at a given time, given its own individual capabilities, punctually. Although ships tend to have a substantial measure of specialization to a primary role (anti-submarine, anti-air, anti-surface, and including the non-specialization of "general purpose"), all retain one or more secondary capabilities. So the failure or loss of one ship does not necessarily mean helplessness to the task force (when it does, then a given ship or component is deemed mission-critical and treated accordingly), only decreased effectiveness, which can be made up by numbers if replacement specialists are not immediately available. Further, as soon as one task is complete, the task force can be broken 
up, its ships and components reassigned to other missions where their primary or secondary capabilities have a role to play. This explains why ships of very different age (and thus of very different technological states of the art, and very different performance) can prove useful. As it is the pairing between individual capabilities and one punctual, limited aspect of the task that is central to effectiveness, state of the art homogeneity tends to be largely a matter of scale economies at acquisition and maintenance (by far the largest cost over the service life of sea systems), not of fitness to purpose for operations against a benchmark of the most advanced technological state of the art. Sufficiency suffices. Any consideration of a sea fleet must take into account this task-oriented technological bias or gravely misperceive its capabilities (Dunnigan, 1993; O’Hanlon, 2009).

As a result of the flexible, task-oriented combination of its various components, polities face stately recurrent choices in the force design of sea fleets. It is the palette of ship (and, depending on context and circumstance, other component's) capabilities that corresponds to the expectations of capabilities of a sea fleet. This distinctive complementarity of various components on a case by case basis means polities have to consider what existing ships can do, shifting their importance but keeping them at hand over long periods of time. A ship's service life can last for decades, from prime combatant, to second line, to lesser roles. Although there might be a measure of advantage in terms of scope and, conceivably, even in terms of scale to adhere to a given technological state of the art, this is not inherently necessary. Affiliation to a given defense industrial base and thus the simplification of the land-based support structure is largely a matter of costs and opportunity. The specific items of the strategic portfolio of a given polity can be effectively, and might even be more economically, addressed by choices of the best ships available that can carry them out-by modernizing, acquiring or building ships. However, it is rare for a sea fleet to possess all of its ships aligned to the same technological state of the art. Most polities explore the flexible combination of differing capabilities and choose opportunistically to assemble ships from different technological states of the art. There are costs involved in such choices in terms of the multiplication of the land-based support structures and the need to ensure a modicum of interoperability in terms of communication and, more rarely, sensors and munitions. Whether this additional cost is offset by economies elsewhere is simply part of the decision process for force design. Sea fleets deal quite easily with the burden of taking into consideration the different capabilities and requisites that stem from the various states of the art, standards and performance of its ships. The lead times for construction, the long service lives, the acquisition of second hand ships point to the final element of the way a sea fleet integrates its capabilities. If on the one hand it integrates its capabilities by echeloning primary and secondary ship capabilities in pursuit of a mission while carrying out a given task, on the other it also echelons in time the integration of the palette of different performances, standards and technological states of the art. 


\section{The inductive combination of ground troops}

The benefits that accrue from the ability to move forces and supplies, to use force on land, notably against opposing force, for international political purposes are germane to the assessment, decision-making, discussion and analysis of international relations. The dynamic of land forces is relevant to a wide variety of situations. These include the assertion of claims or rights of sovereignty; the interdiction of illegal drug, merchandise and people trafficking; the control of territories and populations, their activities and movement; the surveillance of borders, international areas, interposition zones, positions and territories in pursuit or support of international security and peace-building; the exercises of international environmental, commercial and emigration controls and peace keeping operations; the observation and enforcement of embargoes, security zones and cease-fires; the implementation of peace-enforcement; the security, safety and delivery of humanitarian relief. These are all in addition to the role of land forces for counter-insurgency, conventional warfare, nuclear, chemical and biological warfare for the purposes of national defense. The current and prospective technological state of the art of land forces underpins the appreciation of the role they may come to play in international relations: it is the appreciation of the prospects of success by the application of direct and immediate compellence, "boots on the ground" (Tuck, 2014).

A polity's ground troops comprise all combat, combat support and service support components of a polity's fighting force that aim to fight on land. Ground troops result from a complex, multi-varied and irregular decision-making process. It takes into account the context, both in terms of the geographical realities that are politically relevant and in terms of the political relationships that are strategically pertinent. Those responsible for the political direction of a polity enunciate and modify existing and prospective ground troops in terms of policy direction and force design. They take into account the alternative states of the art at the moment a decision is required, considering the availability of resources, the expectation of returns, and the estimates of risk associated with a given configuration of policy and force design, appreciating the benefits of the use of the air and of the sea. From the point of view of the command of ground troops, the result is a strategic portfolio of expectations and goals, missions and responsibilities which translates into a set of means, modes of operation and methods that provide those capabilities that can best approximate the political goals enunciated by policy. The technological dynamic of land forces is as diverse, multivariate and flexible as the roles they may be called to play in peace, war and international "exercises". This requires an appreciation of the particular manner by which technology is used in providing ground troops' capabilities before its consequences to force design can be appreciated. 
The way technology may enable capabilities in land forces illuminates the choices made by polities in the acquisition and composition of their ground troops. To take the capabilities of ground troops by their cumulative arsenals is to miss the tree that might bear the desired fruit for the forest. Albeit the performance parameters of individual units and specific items of equipment may be paramount to what land forces can and cannot, this is confined to narrow circumstances in a matchup between capability and situation (mountain-trained troops in mountain, e.g.). Furthermore, ground troops are, in fact, largely capable of mutual facilitation, and this can drastically modify this simplified perception of their dependency on a given equipment or even a given training. A large part, if not the whole of the soldiers of ground troops can be brought to bear through the leverage of specific, even unique capabilities of individual units (once the mountain troops have opened the way, the others may follow, e.g.). Ground troops are particularly versatile and adaptive. They may benefit and exploit individual capabilities in many cooperative ways both within and between units of various sizes. This corresponds to the fundamental tactical tenet of contemporary ground operations: combined arms. It is important to realize that combined arms, although originally essentially related to the combatant arms (succinctly, infantry, cavalry, artillery) admits expansion to the full plethora of combat support and service support organizations (Dunnigan, 2003; Stoneberger, 2005).

Ground troops are, and in fact must be, articulated, organized and operated as teams-of-teams-of-soldiers, as (i) each unit may possess capabilities or performance that no other unit possess and yet (ii) those capabilities can enable the whole to act largely as if all units possessed such capabilities. This distinctive aspect of ground troops derives primarily from the inherent multi-faceted capabilities of the main component of land forces, infantry. Soldiers may enable the facilitation and be amenable to the adaptation of their own actions as a result of the specific capabilities of other combat, combat support and service support units expediently. The effectiveness of land forces must take into account the effects of induction of the specific capabilities of just a few or even just one of its component units. It is this prospect that better expresses the expectations of what ground troops can and cannot do, and thus ground troops admit various profiles in terms of equipment, performance and specialization. Ground troops are peculiarly dependent on the quality of its personnel, this puts a premium on leadership and technical competence of its leaders and commanders. In fact, ground troops may effect quasi-specialist results from the combination of largely heterogeneous components, so long as units retain the ability to facilitate the action of one another: ground troops benefit from combined induction.

As a result of this distinctive leverage of capabilities, polities face a delicate balancing act in the composition of their ground troops, and are often reluctant to effect major changes in force design. They must account for needs of scale over time: succinctly, adequate numbers to provide readiness, undertake and if necessary 
sustain operations. They must also account for considerations of scope as required: succinctly, specialization to offer different capabilities at adequate standards of performance. And they must deal with the consequences of their choices in terms of the trade-off between inferior solutions by one criterion that are superior by the other. Scale favors adherence to a given technological state of the art, which may however severely limit capabilities. Such adherence can have diverging effects, depending on the technological state of the art: there is a threshold that enables local autonomy in maintenance, more rarely in design and improvement, leading to gains in scope borne out of scale. Scale strongly asserts supplier dependency, but may obviate dependency altogether by making domestic manufacture economical. The need to take one or the other into consideration is one aspect of the strategic portfolio that is particularly telling for land forces (e.g., imported stocks vs. local manufacture of munitions). Considerations of scope are far more diversified and idiosyncratic. Specific capabilities derive from specific items of equipment and training processes. There often correspond to the most capital-intensive pieces of equipment or the most expensive training processes of ground troops, and may have scale requirements of their own. This calls for judicious appreciation of how much is indeed required to provide and sustain the specific capability expected of them. Any consideration of ground troops must take into account the requisites and possibilities of induction by the combination of units or gravely misperceive their capabilities (O'Hanlon, 2009; Black, 2013).

At any given point in time, the state of the art of tactics or logistics admits characterization of optimal solutions, but the composition of sufficiently effective ground troops admits sub-optimal ones at lesser cost or complexity. Furthermore, a given technological state of the art may contain alternatives that can have synergic or, conversely, detrimental effects when juxtaposed, aiding or conversely compromising induction. Finally, any set of choices has to consider and, arguably, justify its decisions against the feasibility of mutual facilitations and combinations. This makes the composition of ground troops a paradoxical exercise in multi-level, multi-criteria and recursive decision-making that arrives at expedient sub-optimal solutions most of the time ("good enough"). In what concerns force design, existing capabilities might be endangered by innovative ones, either producing a period of risk in which neither capability is available, or compromising facilitation, or simply resulting in the net loss of both. The need to compose the variety of units of ground troops in terms of scale, capabilities and facilitation puts a premium on leadership at all levels, with certain command ranks being more critical than others depending on the technological state of the art ground troops adhere to. This puts a considerable planning, testing, evaluation and control burden on the workings of the central planning staffs of land forces, upon whose advice political decision-making relies. 


\section{Final remarks}

The concrete armed forces (air force, navy, army e.g.) of a country are subject to the dynamic discussed above for air fleets, sea fleets and ground troops to the extent that these are part of their strategic portfolio. To the extent of the relative share of its responsibilities for fighting in the air, at sea or on land, concrete military organizations will take technological problem setting and solution seeking in accordance with the preponderant outlook of its combatant environment. This sheds some light on the way acquisition, international technological cooperation, shared research and development or domestic research for combatant purposes is differentiated among armed services and over time.

The different ways of dealing with the state of the art of technology for combatant purposes do offer contrasting views of problem formulation and solution seeking for tactical (use of force) and logistical (force creation, maintenance, disposition, displacement) purposes. Fundamentally, this is a result of the relationship between the functional and strategic responsibilities of fighting in the air, at sea or on land, and the specific consequences of the tactical and logistical requirements of this fighting in what concerns the choices and, above all, the integration of components from differing technological states of the art.

In what concerns the technological dynamic of the state of the art of air fleets, the logic of systemic integration leaves very little room but that of constant efforts towards homogenization at a given technological state of the art (not necessarily the most advanced). To deal with acquisition more explicitly, this means that "buying a new component" is never quite buying just this one component, but rather buying along either an existing system with which it is compatible, or accepting the burden of engineering the whole system so that it will be compatible with it. A brief note, for the sake of completeness, is that this is not just a matter of cost-in fact, maintenance costs are much larger than acquisition costs. What is at stake is the need to align each and every addition to the air fleet system to the same technological state of the art, or to risk either the disharmonious effects of having as many air fleets as there are technological states of the art, or not having an air fleet at all, but only a disjoined collection of components.

In contrast, the technological dynamic of the state of the art of sea fleets admits echeloning both in terms of capability and, thus, indirectly, in terms of time. This admits being subsumed strictly in terms of capability in analytical terms. To deal with acquisition more explicitly, this means that one might conceivably acquire a brand new component, or ship, that is built according to an older or less capable state of the art. If the missions envisioned in the strategic portfolio do not call for more, then this might be simply more economical and sufficient. However, the more usual situation is that of having or considering the acquisition of older components or ships, and having to deal with the choice and costs of keeping them 
as they are, upgrading specific capabilities that would give them a new lease of usefulness, or forsaking them altogether. A brief note, for the sake of completeness, is that this is not just a matter of cost-just like air fleets, maintenance costs are much larger than acquisition costs in sea fleets. The serviceability of ships and many components of a sea fleet require long periods of downtime, so that "buying one" of anything means buying more than one, so as to support the expectation of actually having the use "of one" whenever required. Alternatively, having just the actual single one means accepting that its use is conditional on a substantial degree of preparation and forewarning, enduring the risk of needing it and not having it.

The technological dynamic of the state of the art of ground troops is by far the most distinctive. The prospect of inducted combination puts a potentially decisive premium on aspects that are extremely difficult to measure or even to evaluate, whenever the human elements becomes preponderant. To deal with acquisition more explicitly is to a large extent to simplify matters, because the choices between scale and scope for a given set of capabilities are more tractable than the broader consideration of facilitation through combined arms. That being said, however, the issue admits three brief remarks that might do as boundaries. The first has to do with the demand for differentiated capability and its consequences for scope (and, indirectly, scale): the consideration of the acquisition of a given set of equipment or skills has to be measured against its effective capacity to do something that is not possible to others and that may have combatant import. This would seem to argue strongly in favor of benchmarking capabilities against the most advanced state of the art with no cautions other than those of interoperability, maintainability and serviceability. The second has to do with the demand for readiness and sustainability and its consequences for scale (and, indirectly, scope): the possession of such numbers that allow for the cyclic nature of readiness, the ability to sustain operations over time, and the capacity to expand through reserves or mobilization (either or both of which have to be prepared in advance). This would seem to argue strongly in favor of a number of undifferentiated but versatile units, capable of supplying minimal capabilities as required with no other concern than that of flexibility. These two remarks correspond, in broad terms, to the historical quandary between "specialist" (one job, and one job only, the rest is awareness) and "full spectrum" (to use the contemporary US Army term, but meaning the same as the German Einheit or the British "regulars," fully capable jacks-of-all-trades). This allows the third remark its proper place: that an understanding of the dynamic of the technological state of the art for ground troops strongly suggests that any such choices should be measured against personnel qualification of officers and soldiers that does allow the mutual facilitation of capabilities. Only with ground troops that are the willing and skillful sum of able soldiers the gains of scope of one unit can allow others to follow along and add scale to their joint efforts. This makes personnel qualification potentially dominant in the force design of ground 
troops, which must be sufficiently prepared to possess the possibilities of scope, the numbers of scale, and the preparation to derive the benefits of induction.

It seems reasonable to expect that the more the strategic portfolio of a concrete armed force assigns responsibilities for fighting in different combatant environments, the more it will have to find an accommodation of the differing technological dynamic of multiple states of the art. As a result, it might be advisable for those involved to begin by acknowledging that these differences in dynamic exist in the first place, rather than presuming that a given preponderant organizational outlook offers the only or even the best way forward. Beyond this preliminary caution, however, the matter is perhaps best left as an invitation to empirical research. This might take the form of comparative studies within and between armed forces-for instance, how a given force deals with the needs of air fleet and ground troops, and how another deals with the same needs in its own way.

\section{Bibliographic references}

Bertonha, João Fabio. Brazil: An emerging military power? The problem of the use of force in Brazilian international relations in the 21 (st) century. Revista Brasileira de Politica Internacional. 53 (2): 107-124, 2010.

2013. The national defense strategy of Brazil and other BRICs in a comparative perspective. Revista Brasileira de Politica Internacional. 56 (2): 112-130, 2013.

Black, Jeremy. War and Technology. Bloomington and Indianapolis: Indiana University Press, 2013. Brasil. Estratégia Nacional de Defesa. Brasília: Ministério da Defesa, 2008.

Livro Branco de Defesa Nacional. Brasília: Ministério da Defesa, 2012.

Clausewitz, Carl von. On War. Princeton University Press, 1976.

Crabtree, J. D. On Air Defense. Westport, Conn: Praeger, 1994.

Dunnigan, James. F. How to Make War. 4 edition. New York: William Morrow Paperbacks, 2003.

Gray, Colin S. War, Peace and International Relations: An introduction to strategic history. 2 edition. Abingdon, UK; New York: Routledge, 2011.

Weapons Don't Make War: Policy, Strategy, and Military Technology. Lawrence, Kan: University Press of Kansas, 1993.

Hughes Jr, W. P. Fleet Tactics and Coastal Combat. 2 edition. Annapolis, Md: Naval Institute Press, 2010.

Klein, J. J. Space Warfare: Strategy, Principles and Policy. London: Routledge, 2006.

Murphy, J. D.; McNiece, M. A. Military Aircraft, 1919-1945: An Illustrated History of Their Impact. Santa Barbara: ABC-CLIO, 2008.

O'Hanlon, Michael E. The Science of War: Defense Budgeting, Military Technology, Logistics, and Combat Outcomes. Princeton University Press, 2009. 
Proença Júnior, Domício and Érico Esteves Duarte. Strategic studies as the core discipline of national defense. Revista Brasileira de Politica Internacional. 50 (1): 29-46, 2007.

. The Concept of Logistics derived from Clausewitz. Journal of Strategic Studies. 28(4): 645-677, 2005.

Proença Júnior, Domício. Technological promise and fighting advantage. Revista Brasileira de Politica Internacional. 54 (2): 173-188, 2011.

Rudzit, Gunther and Otto Nogami. National security and defense: basic concepts for an analysis. Revista Brasileira de Politica Internacional. 53 (1): 5-24, 2010.

Shaw, Robert L. Fighter Combat: Tactics and Maneuvering. Annapolis, Md: Naval Institute Press, 1985.

Soares Alsina, Jr, João Paulo. Military power as Brazil's contemporary foreign policy tool. Revista Brasileira de Política Internacional. 52 (2): 173-191, 2009.

Speller, I. Understanding Naval Warfare. Routledge, 2014.

Stoneberger, Brett. Combat Leader's Field Guide: 13th Edition. Mechanicsburg, PA: Stackpole Books, 2005.

Till, Geoffrey. Seapower: A Guide for the Twenty-First Century. 3 edition. New York, NY: Routledge, 2013.

Tuck, C. Understanding Land Warfare. London, Routledge, 2014.

Submitted July 12, 2014

Accepted September 2, 2014

\section{Abstract}

The expectation that technological returns from defense expenditure through acquisition, international cooperation and domestic research would further national development underappreciates the different technological dynamic of the armed services. This paper outlines the technological dynamic the stems from fighting in the air, at sea and on land, exemplifying consequences for the case of acquisition.

Keywords: Armed Forces; National Defense; production engineering; science and technology; strategic studies.

\section{Resumo}

A expectativa de que gastos em defesa promoveriam desenvolvimento nacional a partir dos retornos tecnológicos da aquisição, cooperação internacional e pesquisa doméstica subestima as diferenças da dinâmica tecnológica das forças armadas. Este artigo delineia a dinâmica tecnológica decorrente da luta no ar, no mar e em terra, exemplificando suas consequências para a questão da aquisição.

Palavras-chave: Forças Armadas; Defesa Nacional; engenharia de produção; ciência e tecnologia; estudos estratégicos. 